\title{
Left atrial remodeling by MRI: comparison in patients with and without cardiovascular disease
}

\author{
Dana C Peters ${ }^{1 *}$, Bethlehem Mekonnen ${ }^{1}$, Hamid Mojibian', Mark A Mareib², Gourg Atteya², Daniel Cornfeld ${ }^{1}$ \\ From 17th Annual SCMR Scientific Sessions \\ New Orleans, LA, USA. 16-19 January 2014
}

\section{Background}

Pre-existent scar in the left atrium (LA) is hypothesized to be the arrhythmic substrate of atrial fibrillation (AF) $[1,2]$, and has been characterized in cardiac MR studies [3] using high resolution late gadolinium enhancement (LGE) [4]. Recent pathology studies show that LA fibrosis extent is similar in patients with AF vs. other cardiovascular disease (CVD) [5], e.g. valvular disease, ischemic and non-ischemic cardiomyopathies. Our aim was replicate these pathology findings by comparing patterns of enhancement on LGE in patients with and without CVD.

\section{Methods}

Forty-eight patients were imaged at our center on a $1.5 \mathrm{~T}$ scanner (MAGNETOM Espree, Siemens Healthcare, Erlangen), having good-quality LGE studies with visibly enhanced mitral valves, and no prior pulmonary vein isolation. Left atrial LGE was obtained using an ECG-triggered, navigator-gated 3D GRE inversion recovery (IR) sequence obtained 10-20 minutes after the administration of 0.2 $\mathrm{mmol} / \mathrm{kg}$ of Gadobutrol, with spatial resolution of $1.5 \times$ $1.4 \times 3 \mathrm{~mm} 3$. A blinded assessment of enhancement/scar $(0=$ absent, $1=$ present $)$ was performed in an 18 segment

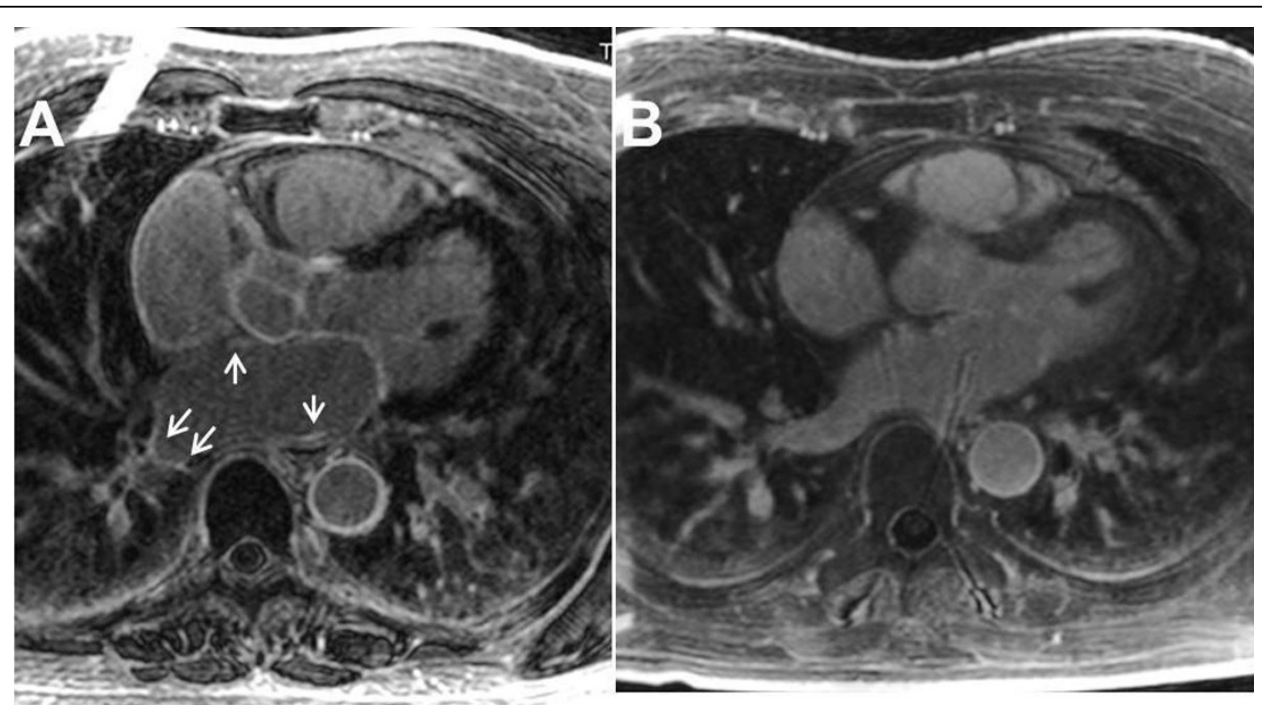

Figure 1 A) 62 y.o. man with ventricual tachycardia, an enlarged right atrium and a scar score $=\mathbf{8 3} \%$ (see arrows). B) 58 y.O. man without CVD, and a scar score $=5 \%$.

${ }^{1}$ Diagnostic Radiology, Yale School of Medicine, New Haven, Connecticut,

USA

Full list of author information is available at the end of the article

(c) 2014 Peters et al.; licensee BioMed Central Ltd. This is an Open Access article distributed under the terms of the Creative Commons 
Table 1 Characteristics for patients with high and low scar scores.

\begin{tabular}{cccc}
\hline & All & High Scar Score & Low Scar Score \\
\hline Age (years) & $46 \pm 19$ & $46 \pm 22$ & $46 \pm 16$ \\
\hline Male & $58 \%$ & $54 \%$ & $62 \%$ \\
\hline LV EF & $51 \pm 14$ & $49 \pm 18$ & $52 \pm 8$ \\
\hline LV EDV & $158 \pm 39$ & $153 \pm 48$ & $163 \pm 30$ \\
\hline BMI (kg/m^2) & $27 \pm 6$ & $27 \pm 6$ & $29 \pm 6$ \\
\hline RA enlargement (\%)* & $26 \%$ & $44 \%$ & $11 \%$ \\
\hline LA enlargement $(\%)^{* *}$ & $25 \%$ & $35 \%$ & $16 \%$ \\
\hline Hypertension $(\%)^{* * *}$ & $43 \%$ & $27 \%$ & $60 \%$ \\
\hline
\end{tabular}

${ }^{* * *} p=0.18,{ }^{* *} p=0.25,{ }^{*} p=0.05$, Fisher's exact test.

model. Segments included 4 regions around each PV, and the LA posterior wall and inter-atrial septum. The total scar score was the $\%$ of enhanced segments. A chart review was performed to obtain clinical data.

\section{Results}

Figure 1 compares LGE images from our cohort. Patients with no CVD ( $=11$, typically subjects with a family history of inheritable CVD) had a lower scar score than patients with CVD $(\mathrm{N}=37$, with a wide range of cardiovascular disease types) $(19 \pm 14 \%$ vs. $38 \pm 21, \mathrm{p}=0.018)$. Six AF patients had a similar scar score to patients with other CVD $(34 \pm 21 \%$ vs. $39 \pm 24 \%)$. Table 1 shows correlations between high scar score and right atrial enlargement, but no other analyzed variables. LA enlargement itself was associated with increased age ( $40 \pm 19$ vs. $55 \pm$ $17, \mathrm{p}=.046)$ and an insignificantly higher BMI $(26.7 \pm 4.0$ vs. $29.7 \pm 5.5, \mathrm{p}=0.14)$, similar to what has been reported previously [6].

\section{Conclusions}

This retrospective analysis found that LA LGE was greater in subjects with CVD vs. those with no CVD, corroborating pathology studies of LA fibrosis. LA LGE enhancement was associated with atrial enlargement. Non-invasive LGE provides a potentially powerful tool for determining clinical factors implicated in LA fibrosis, which would add to the understanding of its causes.

\section{Funding}

\section{NIH (NHLBI R21 HL 098573 \& R21 HL103463).}

\footnotetext{
Authors' details

'Diagnostic Radiology, Yale School of Medicine, New Haven, Connecticut, USA. ${ }^{2}$ Cardiology, Yale School of Medicine, New Haven, Connecticut, USA.

Published: 16 January 2014

\section{References}

1. Thiedemann KU, Ferrans VJ: Am J Pathol 1977, 89:575-604.

2. Verma A, et al: JACC 2005, 45:285-292.
}

3. Oakes RS, et al: Circ 2009, 119:1758-1767.

4. Peters DC, et al: Radiology 2007, 243:690-695.

5. De Oliveira IM, et al: Cardiovasc Pathol 2012.

6. Vaziri SM: Hypertension 1995, 25(6):1155-60.

doi:10.1186/1532-429X-16-S1-P152

Cite this article as: Peters et al:: Left atrial remodeling by MRI:

comparison in patients with and without cardiovascular disease. Journal

of Cardiovascular Magnetic Resonance 2014 16(Suppl 1):P152.
Submit your next manuscript to BioMed Central and take full advantage of:

- Convenient online submission

- Thorough peer review

- No space constraints or color figure charges

- Immediate publication on acceptance

- Inclusion in PubMed, CAS, Scopus and Google Scholar

- Research which is freely available for redistribution

Submit your manuscript at www.biomedcentral.com/submit 